\title{
Elucidating the pathophysiology of syringomyelia
}

John D. Heiss, M.D., Nicholas Patronas, M.D., Hetty L. DeVroom, R.N., Thomas Shawker, M.D., Robert Ennis, B.S., William Kammerer, M.D., Alec Eidsath, Ph.D., Thomas Talbot, M.S., Jonathan Morris, B.S., Eric Eskioglu, M.D., and Edward H. Oldfield, M.D.

Surgical Neurology Branch, Clinical Radiology, Clinical Anesthesia, and Biomedical Engineering, National Institute of Neurological Disorders and Stroke, National Institutes of Health, Bethesda, Maryland

Object. Syringomyelia causes progressive myelopathy. Most patients with syringomyelia have a Chiari I malformation of the cerebellar tonsils. Determination of the pathophysiological mechanisms underlying the progression of syringomyelia associated with the Chiari I malformation should improve strategies to halt progression of myelopathy.

Methods. The authors prospectively studied 20 adult patients with both Chiari I malformation and symptomatic syringomyelia. Testing before surgery included the following: clinical examination; evaluation of anatomy by using $\mathrm{T}_{1}$-weighted magnetic resonance (MR) imaging; evaluation of the syrinx and cerebrospinal fluid (CSF) velocity and flow by using phase-contrast cine MR imaging; and evaluation of lumbar and cervical subarachnoid pressure at rest, during the Valsalva maneuver, during jugular compression, and following removal of CSF (CSF compliance measurement). During surgery, cardiac-gated ultrasonography and pressure measurements were obtained from the intracranial, cervical subarachnoid, and lumbar intrathecal spaces and syrinx. Six months after surgery, clinical examinations, MR imaging studies, and CSF pressure recordings were repeated. Clinical examinations and MR imaging studies were repeated annually. For comparison, 18 healthy volunteers underwent $\mathrm{T}_{1}$-weighted $\mathrm{MR}$ imaging, cine MR imaging, and cervical and lumbar subarachnoid pressure testing.

Compared with healthy volunteers, before surgery, the patients had decreased anteroposterior diameters of the ventral and dorsal CSF spaces at the foramen magnum. In patients, CSF velocity at the foramen magnum was increased, but CSF flow was reduced. Transmission of intracranial pressure across the foramen magnum to the spinal subarachnoid space in response to jugular compression was partially obstructed. Spinal CSF compliance was reduced, whereas cervical subarachnoid pressure and pulse pressure were increased. Syrinx fluid flowed inferiorly during systole and superiorly during diastole on cine MR imaging. At surgery, the cerebellar tonsils abruptly descended during systole and ascended during diastole, and the upper pole of the syrinx contracted in a manner synchronous with tonsillar descent and with the peak systolic cervical subarachnoid pressure wave. Following surgery, the diameter of the CSF passages at the foramen magnum increased compared with preoperative values, and the maximum flow rate of CSF across the foramen magnum during systole increased. Transmission of 
pressure across the foramen magnum to the spinal subarachnoid space in response to jugular compression was normal and cervical subarachnoid mean pressuree and pulse pressure decreased to normal. The maximum syrinx diameter decreased on MR imaging in all patients. Cine MR imaging documented reduced velocity and flow of the syrinx fluid. Clinical symptoms and signs improved or remained stable in all patients, and the tonsils resumed a normal shape.

Conclusions. The progression of syringomyelia associated with Chiari I malformation is produced by the action of the cerebellar tonsils, which partially occlude the subarachnoid space at the foramen magnum and act as a piston on the partially enclosed spinal subarachnoid space. This creates enlarged cervical subarachnoid pressure waves that compress the spinal cord from without, not from within, and propagate syrinx fluid caudally with each heartbeat, which leads to syrinx progression. The disappearance of the abnormal shape and position of the tonsils after simple decompressive extraarachnoidal surgery suggests that the Chiari I malformation of the cerebellar tonsils is acquired, not congenital. Surgery limited to suboccipital craniectomy, $\mathrm{C}-1$ laminectomy, and duraplasty eliminates this mechanism and eliminates syringomyelia and its progression without the risk of more invasive procedures.

\section{Key Words * syringomyelia * radiography * neurophysiology * Arnold-Chiari malformation}

With a prevalence of 8.4 cases per 100,000 population, approximately 21,000 Americans have syringomyelia, a disorder in which a cyst forms within the spinal cord, resulting in myelopathy.[6] Symptoms of paralysis, sensory loss, and chronic pain commonly develop during the second through fifth decades of life. The natural history of syringomyelia is typically one of gradual, stepwise neurological deterioration extending over many years.[5] Syringomyelia is usually associated with an inferior position of the cerebellar tonsils through the foramen magnum: the Chiari I malformation.[7] The objective of surgical treatment of syringomyelia associated with Chiari I malformation is to eliminate the syrinx and prevent progression of myelopathy.

Despite four decades of investigation and discussion of the pathogenesis responsible for the progression of syringomyelia associated with Chiari I malformation, the pathophysiological mechanisms remains poorly defined and controversial. Because the cerebrospinal fluid (CSF) pathways at the foramen magnum are encroached on by the Chiari malformation and because syrinx fluid is identical in chemical composition to CSF, theories were developed to explain syrinx formation on the basis of abnormal CSF physiology. These theories suggested that the syrinx developed and progressed from expansion of the central canal of the spinal cord by CSF pulse pressure waves or craniospinal pressure differentials transmitted from the fourth ventricle to the syrinx.[7,19] Surgical treatments were devised to reduce pressure transmission through the central canal of the spinal cord to the syrinx.[7,19,20] Although treatments based on these theories met with moderate success, autopsy and radiographic studies rarely demonstrated a patent central canal in adult patients with syringomyelia,[2,21] and thus it became clear that development of syringomyelia must occur by another mechanism. Discovery of the pathophysiological mechanism of progression of syringomyelia is vital for selecting surgical treatment.

The purpose of this prospective study was to define the pathophysiology of syrinx development and its resolution with surgery. The study was designed to examine a new theory in which syrinx progression results from this sequence of events: 1) the Chiari malformation partially obstructs CSF pathways at the foramen magnum; 2) the normally rapid efflux and influx of CSF between the head and the spine, which compensates for brain expansion and contraction during the cardiac cycle, is blocked; 3) the cerebellar tonsils are displaced during the cardiac cycle, in lieu of CSF, creating a piston effect on the partially 
enclosed spinal subarachnoid space; 4) enlarged cervical subarachnoid pressure waves are created, which compress the spinal cord from without, direct CSF into the spinal cord, and cause pulsatile syrinx flow; and 5) this leads to syrinx progression.[12]

\section{CLINICAL MATERIAL AND METHODS}

\section{Study Protocol}

Twenty patients, mean age $34.6 \pm 11.6$ years (standard deviation) (range 16-51 years) with both progressive syringomyelia and Chiari I malformation were enrolled in a clinical research protocol, "Establishing the Physiology of Syringomyelia Study (NINDS 92-N-0226)." In addition, 18 normal adult volunteers, age 33.2 \pm 9.3 years (range 23-61 years) were enrolled in a clinical research protocol, "Establishing Normal CSF Physiology to Allow Comparison with Syringomyelic CSF Physiology (NINDS 94-N-0160)." The Institutional Review Board of the National Institute of Neurological Disorders and Stroke (NINDS) approved the research protocols. Informed consent was obtained from each adult patient, the parents of the 16-year-old patient, and each healthy volunteer. All patients and healthy volunteers were evaluated and treated at the Clinical Center of the National Institutes of Health, Bethesda, Maryland.

All patients had progressive myelopathy caused by syringomyelia. The patients' symptoms had been present for 0.25 to 15 years (mean $3.2 \pm 4.3$ years) before surgical treatment was performed.

\section{Preoperative Evaluation}

Radiological Imaging of Anatomy. Three independent examiners evaluated midsagittal $\mathrm{T}_{1}$-weighted magnetic resonance (MR) images of the posterior fossa and the cervical and thoracic spine. Low-signal areas were measured to determine the maximum anteroposterior (AP) diameter of the syrinx, the length of the syrinx, the AP diameter of the CSF pathways ventral and dorsal to the neural elements at the foramen magnum, the size of the lateral ventricles, and any evidence of connection between the syrinx and the fourth ventricle. The spatial relationship of the most caudal portion of the cerebellar tonsils to the foramen magnum and the morphological characteristics of the cerebellum were also assessed. Finally, the size of the posterior fossa was estimated by measuring: 1) the length of the suboccipital bone, the entire clivus, and the portion of the clivus below the synchondrosis; and 2) the angle of the tentorium with respect to a line between the torcula and the tuberculum sellae (Twining's line).[10,18]

Radiological Imaging of Physiology. Phase-contrast cine MR imaging was used to measure movement of the fluid in the syrinx, movement of CSF at the foramen magnum, and movement of CSF in the subarachnoid space ventral and dorsal to the spinal cord at the level of the C5-6 intervertebral disc.

Spinal Subarachnoid Pressure Recording and Physiological Testing. Preoperative testing of thecal and cervical subarachnoid pressures was performed after insertion, using fluoroscopic guidance, of 22-gauge spinal needles at the C1-2 and L4-5 levels. Pressures were recorded at rest, during the Valsalva maneuver, and during jugular compression (Queckenstedt's test). The Valsalva maneuver consisted of the patient blowing into a plastic tube at a pressure of $40 \mathrm{~mm} \mathrm{Hg}$ for 12 seconds.[20] Jugular compression was performed by rapidly inflating a blood pressure cuff around the patient's neck to a pressure of $60 \mathrm{~mm}$ $\mathrm{Hg}$. The rates of rise and fall of pressure (millimeters of mercury per second) were measured.[8,16] Compliance (milliliters of CSF per millimeters of mercury) was measured by dividing the amount of CSF removed $(10 \mathrm{ml})$ by the reduction in mean intrathecal pressure (in millimeters of mercury) that 
resulted from CSF removal. Pressures were recorded on the hard disk drive of a computer by using a system of Sorenson pressure transducers, a physiological monitor, an analog-to-digital converter board, and data acquisition software. Recordings were displayed using graphic computer software. The pressure transducers were calibrated with a static water column.

\section{Testing During Surgery}

Physiological Testing. During surgery, catheters were placed into the right lateral ventricle and the thecal sac at L4-5. Baseline recordings were obtained. After the cervical dura had been exposed but not opened, 22-gauge spinal needles were inserted into the cervical subarachnoid space and the syrinx by using ultrasound imaging for guidance. Baseline recordings were repeated. The rates of rises in intracranial, cervical, syrinx, and intrathecal pressures in response to jugular compression and the Valsalva maneuver (positive pressure ventilation to $40 \mathrm{~mm} \mathrm{Hg}$ for 12 seconds) were measured.[20]

Intraoperative Imaging. The operative procedure in all patients was a suboccipital craniectomy, upper cervical (C-1 and C-2) laminectomy, opening of the dura leaving the arachnoid intact, and duraplasty. In cases in which the syrinx did not extend cephalic to C-2, a C-7 laminectomy was performed before the suboccipital craniectomy to allow ultrasonic visualization of the spinal cord before decompressing the craniocervical junction. After suboccipital craniectomy and laminectomy, but before opening the dura, we used a 7-mHz linear transducer and an ultrasound unit to record images and electrocardiography traces simultaneously on videotape. Using this videotape, we reviewed ultrasound images at 100 -msec intervals for three cardiac cycles. The AP diameter of the syrinx was measured on each image, and a graph was created comparing the AP diameter of the syrinx and the time after the R-wave. On the ultrasound images, the positions of the tips of the cerebellar tonsils during systole and diastole were measured relative to a millimeter scale on the image; the difference (in millimeters) was the amplitude of caudal movement of the tonsils during systole. Simultaneous CSF (intracranial, cervical subarachnoid, syrinx, and thecal), hemodynamic (central venous and radial artery) pressure, and electrocardiographic findings were plotted. This allowed us to establish the simultaneous relationship of pressures, syrinx size, and cerebellar tonsil pulsation during the cardiac cycle. The response of cerebellar and syrinx pulsation to jugular compression, Valsalva maneuvers, and dural opening was recorded. Ultrasonography was repeated after opening the dura and after placing the dural graft.

\section{Postoperative Evaluation}

Six days after surgery, while the syrinx was still visible, the patients underwent phase-contrast cine MR imaging of the cervical spine. Six months later, they returned to our institution for midsagittal $\mathrm{T}_{1}$-weighted anatomical MR imaging of the posterior fossa and the cervical and thoracic spine, phase-contrast cine MR imaging, and cervical subarachnoid and intrathecal pressure testing.

The clinical results were evaluated before and 12 months after surgery by grading signs and symptoms as "absent," "mild," "moderate," or "severe." Symptoms of headache, dysesthetic pain, extremity weakness, and impaired ambulation, and neurological signs of weakness, atrophy, and ataxia were evaluated. The grades from before and after surgery were compared and each sign or symptom was evaluated as "improved," "no change," or "worse."[3]

\section{Healthy Volunteers}

A control group of 18 healthy volunteers underwent $T_{1}$-weighted and phase-contrast cine $M R$ imaging 
and measurement of cervical subarachnoid and lumbar thecal CSF pressure, as did the patients with Chiari I malformation and syringomyelia. On the basis of these studies, normal values were established for the AP diameter of the CSF pathways at the foramen magnum, for CSF velocity and flow at the foramen magnum and in the cervical subarachnoid space, for cervical and lumbar subarachnoid pressures, and the pressure responses to jugular compression, Valsalva maneuver, and the removal of 10 $\mathrm{ml}$ of CSF (for measurement of compliance).

\section{Statistical Analysis}

Data are expressed as the mean \pm standard deviation. Values obtained in patients before and after surgery were compared with those obtained in the healthy volunteers by using the unpaired Student's t-test. Test values obtained in patients before surgery were compared with those obtained after surgery by using the paired Student's t-test. In cases in which pressure differentials were evaluated between the intracranial and intrathecal spaces or between the syrinx and the cervical subarachnoid space, the paired Student's $\mathrm{t}$-test and regression analysis were performed. A probability value of less than or equal to 0.05 was considered significant.

\section{Sources of Supplies and Equipment}

Phase-contrast cine MR imaging was performed using Signa Advantage Flow Analysis Software, Release 5.4, available from General Electric Medical Systems (Milwaukee, WI). Equipment used to record pressures included a Macintosh computer purchased from Apple Computer, Inc. (Cupertino, CA), a physiological monitor from Spacelabs Medical, Inc. (Redmond, WA), and an analog-to-digital converter board and LabView version 2.0 data acquisition software from National Instruments Corp. (Austin, TX). Recordings were displayed using Kaleidagraph version 3.0.1 graphic computer software obtained from Synergy Software (Reading, PA).

Catheters used during surgery were purchased from Cordis Corp. (Miami, FL), and the Quantum ultrasound unit was obtained from Acuson (Mountain View, CA).

\section{RESULTS}

\section{Preoperative Evaluation}

On MR imaging, the Chiari I malformation was observed to severely narrow the AP diameter of the CSF pathways at the foramen magnum ventral to the medulla oblongata (patients $1.3 \pm 0.7 \mathrm{~mm}$; healthy volunteers $6.2 \pm 1.8 \mathrm{~mm} ; \mathrm{p}<0.0001$ ) and dorsal to the cerebellar tonsils (patients $0 \pm 0.1 \mathrm{~mm}$; volunteers $5.2 \pm 2.6 \mathrm{~mm} ; \mathrm{p}<0.0001$ ) (Fig. 1). 


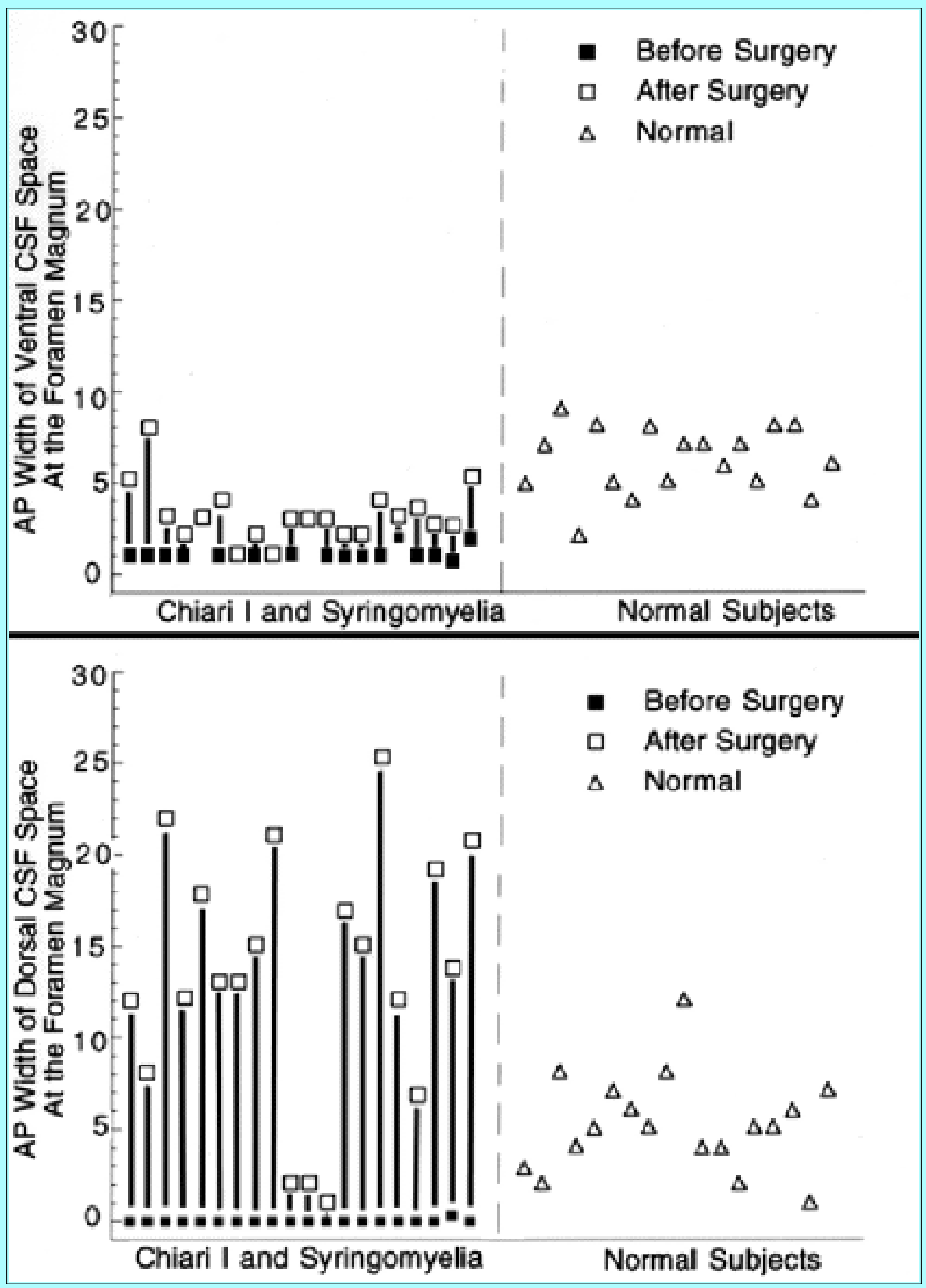

Fig. 1. Graphs showing AP diameters of the subarachnoid space at the foramen magnum in healthy volunteers (normal subjects) and in patients with both Chiari I malformation and syringomyelia, before and after surgery. Diameters were measured ventral to the medulla (upper) and dorsal to the cerebellar tonsils (lower).

Cine MR images obtained at the foramen magnum revealed that the cross-sectional area of the CSF flow pathway was reduced (patients $1.1 \pm 0.6 \mathrm{~cm}^{2}$; volunteers $3.6 \pm 1.4 \mathrm{~cm}^{2} ; \mathrm{p}<0.0001$ ). The cerebellar tonsils consistently exhibited a "pointed" shape, with the tips lying below the foramen magnum (Fig. 2 left). The spinal cord was distended in all cases by syringes, which ranged in diameter from 5 to $11 \mathrm{~mm}$ 
(mean $8.6 \pm 1.5 \mathrm{~mm}$ ) and extended longitudinally 2.4 to $40 \mathrm{~cm}$ (mean $17.3 \pm 10.6 \mathrm{~cm}$ ) (Fig. 2 left). Only one patient had radiographic evidence of communication between the fourth ventricle and the syrinx.

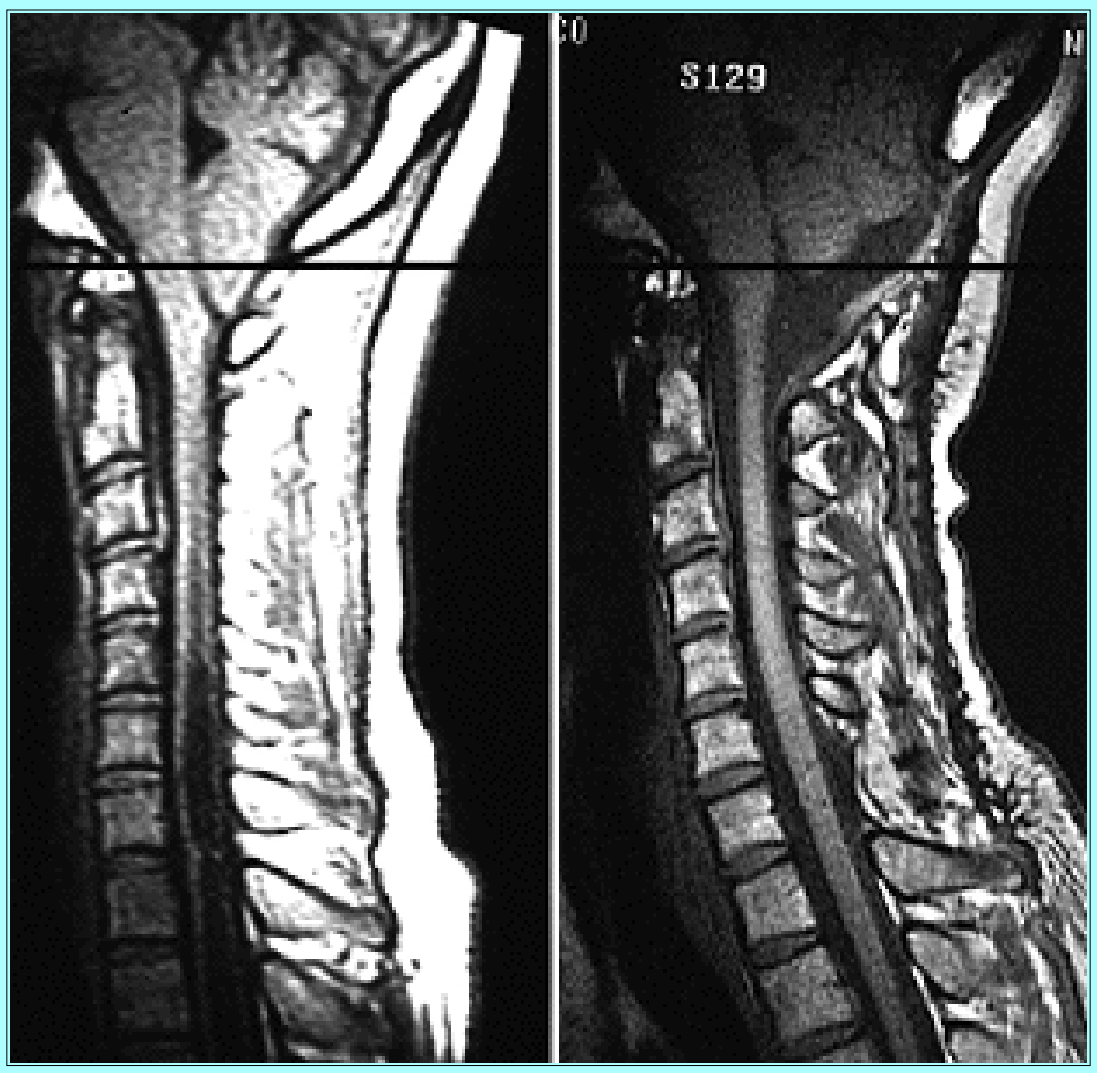

Fig. 2. Magnetic resonance $\mathrm{T}_{1}$-weighted images of the posterior fossa and cervical spine obtained in the midsagittal plane before surgery (left) and after craniocervical decompression and duraplasty (right). After decompressive surgery, the cerebellar tonsils become round and ascend into the posterior fossa, and the subarachnoid space is enlarged ventrally and dorsally. Horizontal black line is added to align the images at the foramen magnum.

Cerebrospinal fluid pressure transmission across the foramen magnum was compromised, as shown by the rate of increase (patients $4.2 \pm 1.8 \mathrm{~mm} \mathrm{Hg} / \mathrm{second}$; volunteers $6.6 \pm 2 \mathrm{~mm} \mathrm{Hg} / \mathrm{second} ; \mathrm{p}=0.001$ ) and the rate of decrease (patients $-11.1 \pm 5.3 \mathrm{~mm} \mathrm{Hg} / \mathrm{second}$; volunteers $-17.2 \pm 8.5 \mathrm{~mm} \mathrm{Hg} / \mathrm{second}$; $\mathrm{p}=0.01$ ) in thecal pressure in response to jugular compression (Queckenstedt's test) (Figs. 3 and 4). 


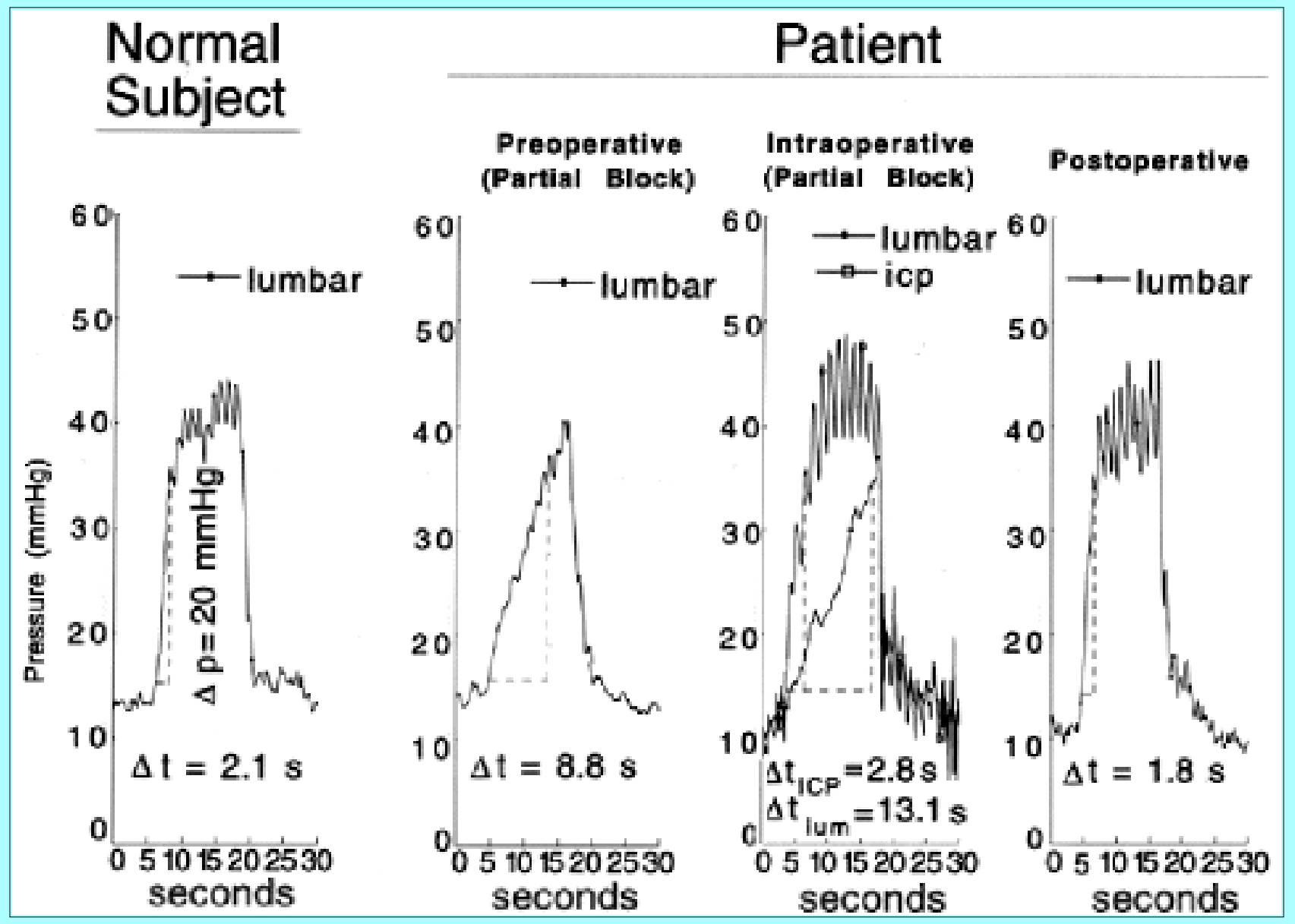

Fig. 3. Pressure recordings showing partial occlusion of CSF flow at the foramen magnum. The rate of rise in intrathecal pressure is shown in a healthy volunteer (normal subject) and in a patient with both Chiari I malformation and syringomyelia before surgery and before the craniocervical junction is decompressed during surgery. After surgery, the rise in intrathecal pressure becomes normal. Abbreviations: icp = intracranial pressure; lum $=$ lumbar, $\mathrm{s}=$ seconds. 


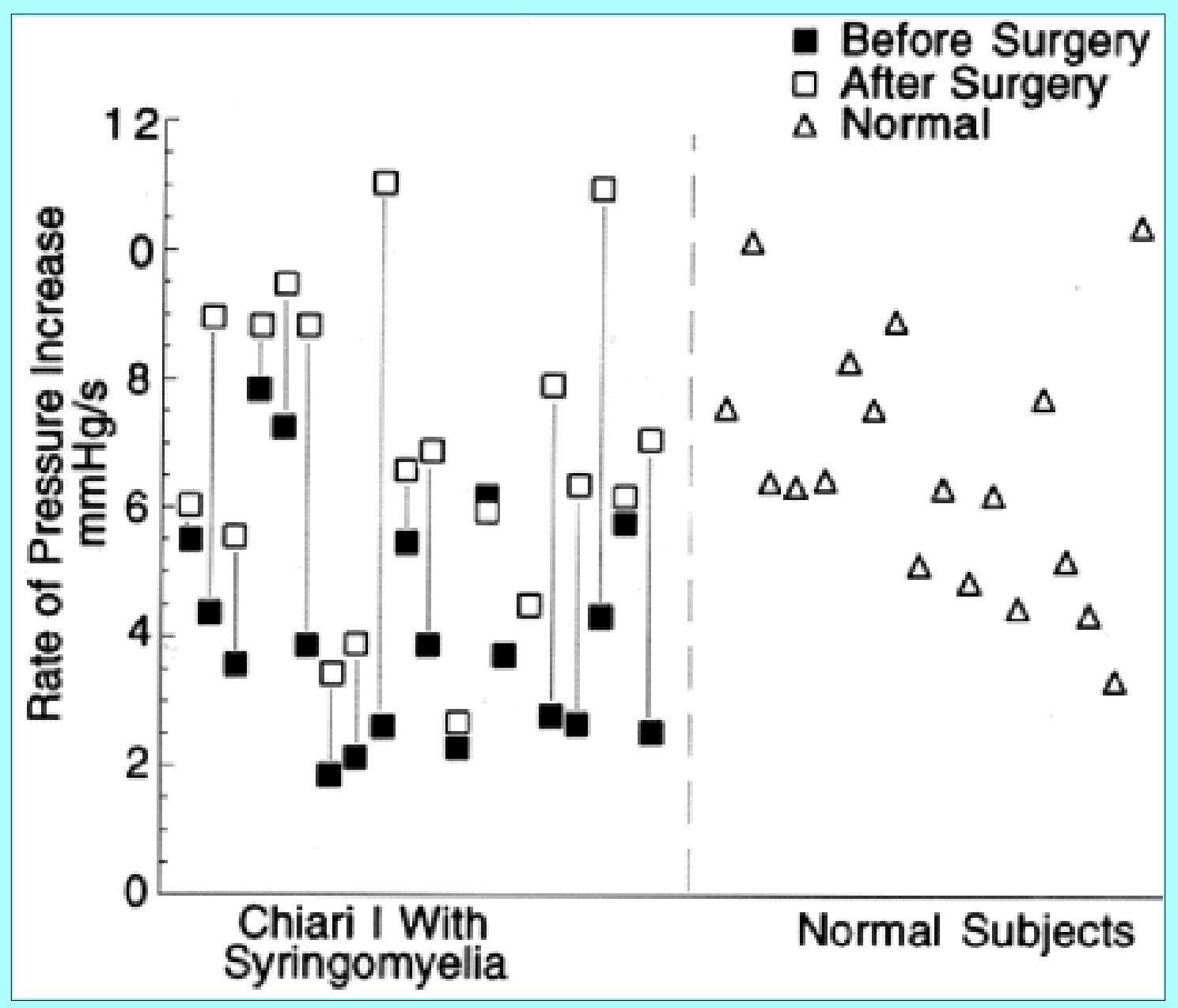

Fig. 4. Scatterplots in which the rates of rise in intrathecal pressure in patients with both Chiari I malformation and syringomyelia with those of healthy volunteers (normal subjects) are compared. After surgery, the rise in intrathecal pressure becomes normal.

At the foramen magnum, cine MR imaging demonstrated that the peak velocity of CSF during the cardiac cycle was increased in the inferior (patients $11.7 \pm 6 \mathrm{~mm} / \mathrm{second}$; volunteers $4.9 \pm 2.8$ $\mathrm{mm} / \mathrm{second} ; \mathrm{p}=0.0005$ ) and superior (patients $-11.5 \pm 5.9 \mathrm{~mm} / \mathrm{second}$; volunteers $-5.9 \pm 4.3 \mathrm{~mm} / \mathrm{second}$; $\mathrm{p}=0.008$ ) directions (Fig. 5 upper). Cine magnetic resonance imaging also revealed abrupt inferior movement of cervical subarachnoid CSF and syrinx fluid during systole and superior movement during diastole (Fig. 5 lower). 


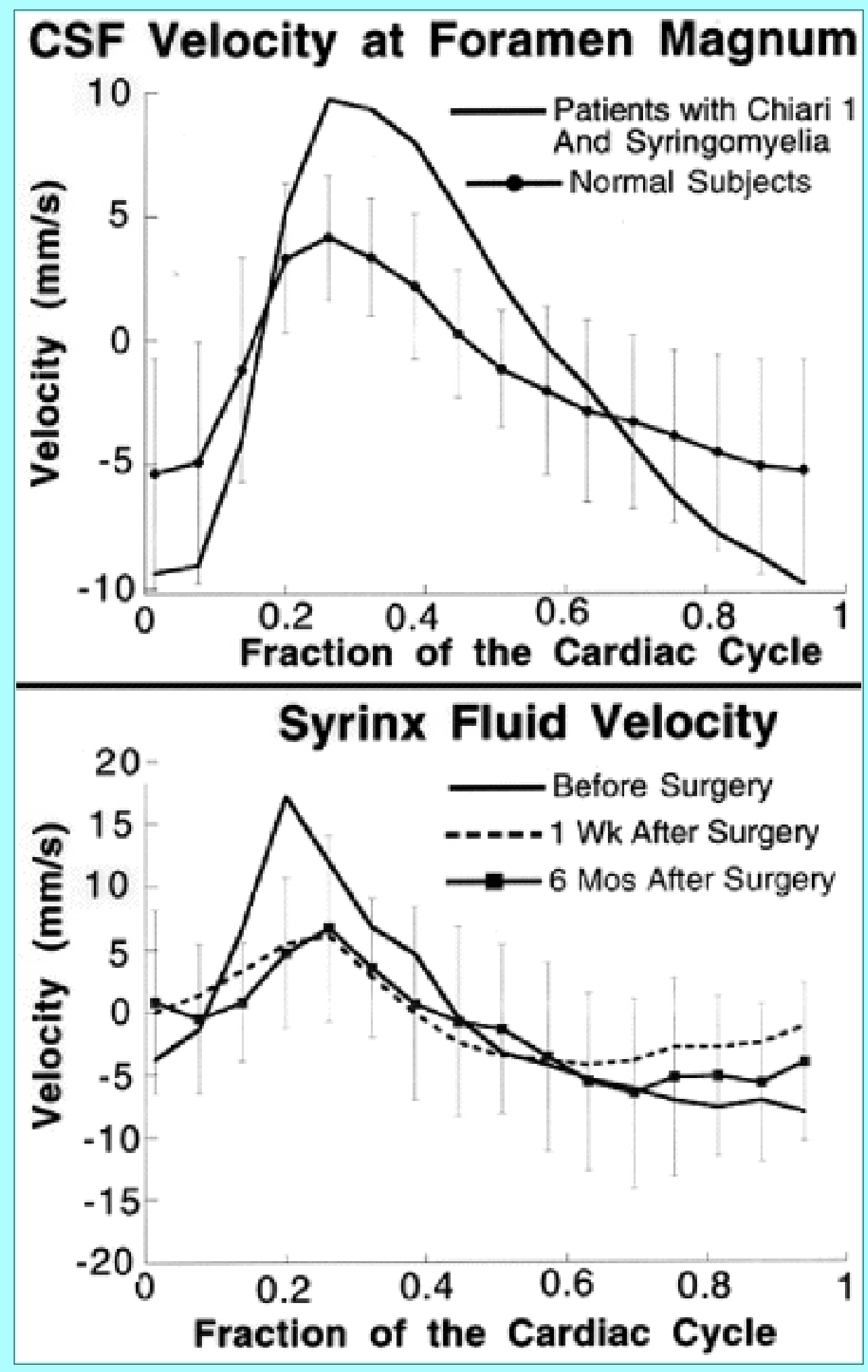

Fig. 5. Graphs displaying the results of phase-contrast cine MR imaging studies obtained in patients and healthy volunteers (normal subjects). In each patient and volunteer, velocity was measured during 16 segments of the cardiac cycle. The mean velocity values for patients and healthy volunteers were plotted against the fraction of the cardiac cycle after the R-wave of the electrocardiogram. Positive values indicate caudal flow, and negative values indicate rostral flow. Error bars indicate one standard deviation from the mean. Upper: Velocity of CSF in the subarachnoid space at the foramen magnum. Lower: Velocity of syrinx fluid in patients before and after surgery. 
Cerebrospinal fluid compliance was low in patients $(3.3 \pm 2.3 \mathrm{ml} \mathrm{CSF} / \mathrm{mm} \mathrm{Hg}$ ) compared with healthy volunteers $(6 \pm 4 \mathrm{ml} \mathrm{CSF} / \mathrm{mm} \mathrm{Hg} ; \mathrm{p}=0.02)$ (Fig. 6). The mean cervical subarachnoid pressure was greater in patients than in healthy volunteers $(15.5 \pm 5.6 \mathrm{~mm} \mathrm{Hg}$ compared with $11.2 \pm 2.5 \mathrm{~mm} \mathrm{Hg}, \mathrm{p}=$ $0.006)$, as was the mean cervical pulse pressure $(2.3 \pm 0.6 \mathrm{~mm} \mathrm{Hg}$ compared with $1.6 \pm 0.6 \mathrm{~mm} \mathrm{Hg} ; \mathrm{p}=$ 0.002 ) (Table 1). The Valsalva maneuver increased cervical subarachnoid and lumbar thecal pressures equally in patients $(38.2 \pm 9.6 \mathrm{~mm} \mathrm{Hg}$ compared with $37.4 \pm 8.9 \mathrm{~mm} \mathrm{Hg}, \mathrm{p}=0.44)$ and healthy volunteers (41.8 $\pm 6.7 \mathrm{~mm} \mathrm{Hg}$ compared with $41.2 \pm 4.7 \mathrm{~mm} \mathrm{Hg} ; \mathrm{p}=0.11)$.

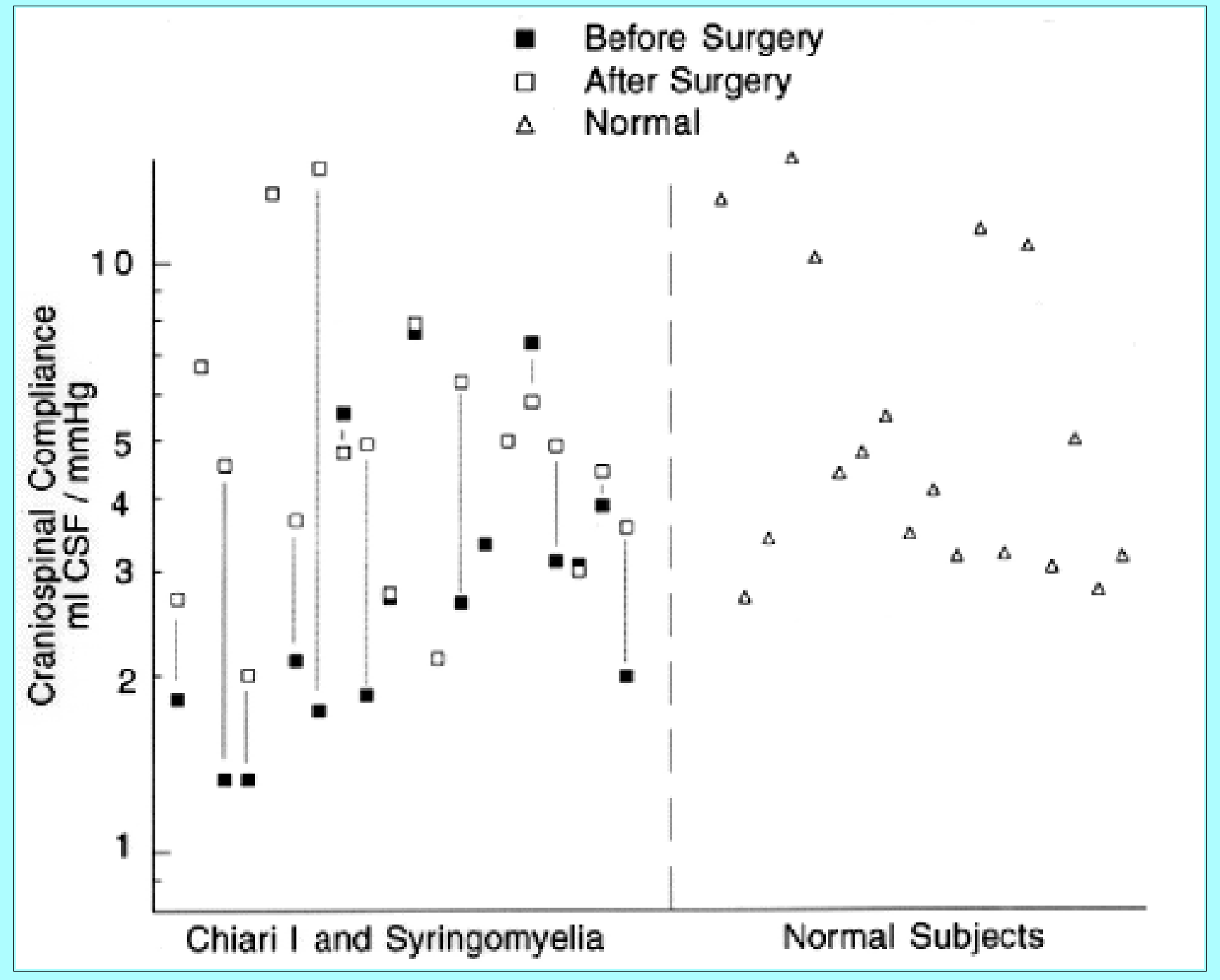

Fig. 6. Scatterplot showing that craniospinal compliance was compromised before surgery and returned to normal after surgery. Compliance was measured by dividing the amount of $\mathrm{CSF}$ removed $(10 \mathrm{ml})$ by the reduction in intrathecal pressure (in millimeters of mercury) that resulted. 


\section{TABLE 1}

PRESSURE RECORD NGS IN 19 PATIENTS WITH BOTH CHIARI I MLLFORMATION AND SYR NGOMVELIA AND 18 HEALTHY YOLUNTEERS ${ }^{\star}$

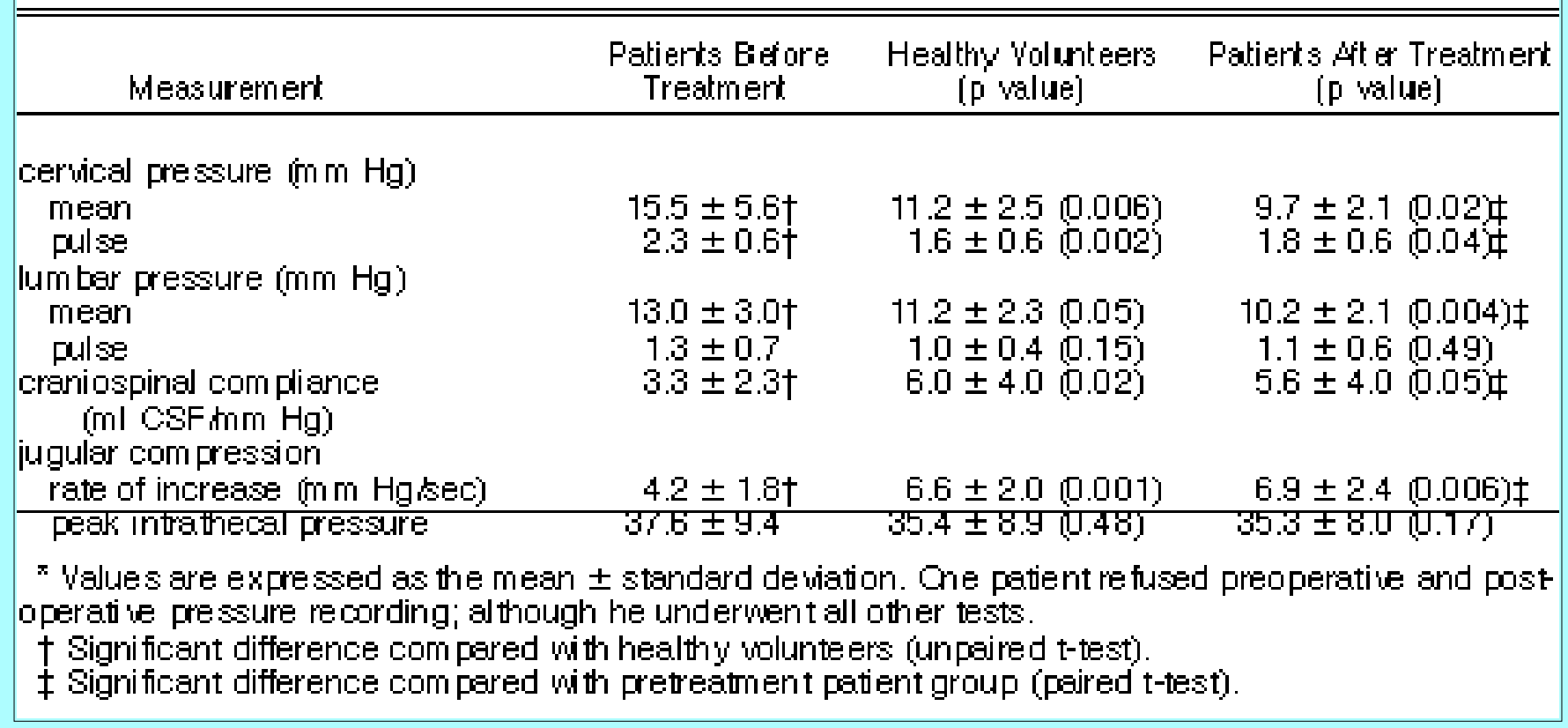

\section{Intraoperative Evaluation}

At surgery, ultrasonography demonstrated that the syrinx contracted in synchrony with tonsillar descent in all patients, including the patient with direct communication between the syrinx and fourth ventricle, as seen on anatomical MR imaging. Using ultrasonography, it was observed that this was the only patient in whom any evidence of a connection between the upper pole of the syrinx and the lower portion of the fourth ventricle could be demonstrated. Simultaneous ultrasonography, pressure testing, and electrocardiographic recording established that the tonsillar descent and syrinx contraction occurred during cardiac systole (200-600 msec after the R-wave) (Fig. 7). 


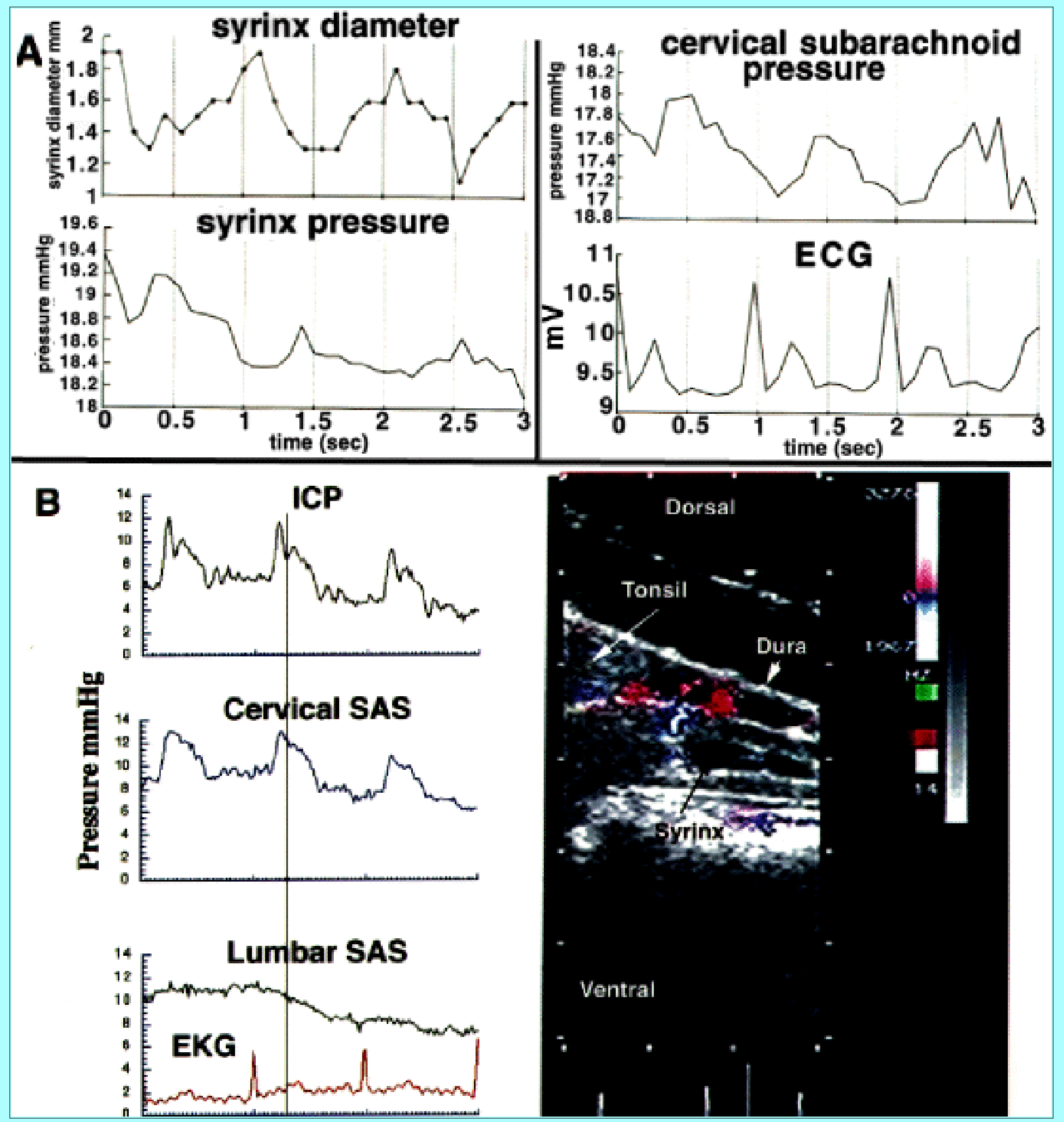

Fig. 7. A. Graphs showing the measurement of syrinx diameter at $\mathrm{C}-2$ by using cardiac-gated, intraoperative ultrasonography simultaneously with pressure recordings within the syrinx and cervical subarachnoid space. The syrinx contracts during cardiac systole when cervical subarachnoid pressure reaches its peak. B. This frame of the QuickTime movie shows simultaneous intraoperative EKG and CSF pressure tracings (left) and intraoperative, cardiac-gated, Doppler ultrasonography in the sagittal plane at the foramen magnum (right).

[Click here to view video clip (2.4 MB).] 
Movie clip: The QuickTime movie animates frames from three cardiac cycles in a patient with Chiari I and syringomyelia. The EKG on the cine-ultrasound (right) scrolls from right-to-left and is synchronized with the vertical line on the EKG pressure graph (left). Flow detected by the Doppler ultrasound is displayed in red (caudal flow) and blue (cephalic flow). The beginning and ending segments of the clip are played at normal speed and the middle segment in slow-motion and freeze frame to demonstrate that tonsillar descent and syrinx contraction occur during cardiac systole.

Syrinx pressure was identical to cervical subarachnoid pressure (syrinx $15 \pm 5.8 \mathrm{~mm} \mathrm{Hg}$; cervical $15.1 \pm$ $4.7 \mathrm{~mm} \mathrm{Hg}$; correlation coefficient $0.997, \mathrm{p}<0.0001$ ). The Valsalva maneuver failed to produce significant pressure differentials between the intracranial and spinal subarachnoid spaces (correlation coefficient 0.932, $\mathrm{p}<0.0001$ ) (Table 2). There was no change in the AP diameter of the syrinx or spinal cord in response to the Valsalva maneuver. Opening of the dura reduced the amplitude of the pulsation of the cerebellar tonsils and eliminated the contraction of the syrinx.

\begin{tabular}{|cccc|}
\hline \multicolumn{4}{c}{ TABLE 2 } \\
INTRAOPERATIVE PRESSURE RECORD NGS IN PATIENTS WITH BOTH \\
CHIARII I MLLFORMATION AND SVR NGOMNELIA太
\end{tabular}

\section{Postoperative Evaluation}

Six months after surgery, $\mathrm{T}_{1}$-weighted MR images of the craniocervical area demonstrated that the CSF space at the foramen magnum had expanded (in the ventral space from $1.3 \pm 0.7$ to $3.2 \pm 1.6 \mathrm{~mm}, \mathrm{p}=$ 0.02 ; in the dorsal space from $0 \pm 0.1$ to $13.4 \pm 6.9 \mathrm{~mm} ; \mathrm{p}=0.0001$ ) (Fig. 1) and that the cerebellar tonsils had ascended and assumed a rounded structure (Fig. 2 right and Table 3 ). 


\begin{tabular}{|c|c|c|c|c|c|}
\hline \multirow[b]{2}{*}{ Feature } & \multicolumn{3}{|c|}{ Patierts } & \multicolumn{2}{|c|}{ Heal thy volunteers } \\
\hline & $\begin{array}{l}\text { Measuremert } \\
\text { Preop }\end{array}$ & $\begin{array}{l}\text { Measuremert } \\
6 \text { kos Postop }\end{array}$ & p Value & $\begin{array}{l}\text { Measure- } \\
\text { mert }\end{array}$ & p Value \\
\hline \multicolumn{6}{|l|}{ syrinx } \\
\hline diameter (mm) & $8.6 \pm 1.5$ & $1.5 \pm 1.7$ & $<0.0001 \dagger$ & - & - \\
\hline length (le vels) & $9.8 \pm 4.7$ & $2.4 \pm 2.9$ & $<0.0001 \dagger$ & - & - \\
\hline length (cm) & $17.3 \pm 10.6$ & $3.6 \pm 4.7$ & $<0.0001 \dagger$ & - & - \\
\hline $\begin{array}{l}\text { tonsillar hemiation below foramen } \\
\text { magnum (mm) }\end{array}$ & $11.1 \pm 5.4$ & $5.5 \pm 3.9$ & $<0.0001 \dagger$ & $0.3 \pm 1.0$ & $<0.0001 \neq$ \\
\hline pointed tonsils (no. of cases) & $15(75 \%)$ & $1(5 \%)$ & $<0.0001 \dagger$ & $0(0 \%)$ & $<0.0001 \ddagger$ \\
\hline $\begin{array}{l}\text { Small cerebellar suld (no. of cases) } \\
\text { foramen magnum CSF pathmay }\end{array}$ & $17(85 \%)$ & $0(0 \%)$ & $<0.0001 \dagger$ & $0(0 \%)$ & $<0.0001 f$ \\
\hline wentral AP diameter ( $\mathrm{mm}$ ) & $1.3 \pm 0.7$ & $3.2 \pm 1.6$ & $<0.0001 \dagger$ & $6.2 \pm 1.8$ & $<0.0001 \neq$ \\
\hline dorsal AP diameter $(\mathrm{mm})$ & $0 \pm 0.1$ & $13.4 \pm 6.9$ & $<0.0001 \dagger$ & $5.2 \pm 2.6$ & $<0.00017$ \\
\hline $\begin{array}{l}\text { Syring-4th wentricle connection } \\
\text { (no. of cases) }\end{array}$ & $1(5 \%)$ & & & & \\
\hline wenticulomegaly (no. of cases) & $4(20 \%)$ & $4(20 \%)$ & & $0(0 \%)$ & \\
\hline torcula-opisthion (cm) & $3.9 \pm 0.6$ & - & - & $4.1 \pm 0.4$ & 0.15 \\
\hline cliwus length (cm) & $4.0 \pm 0.3$ & - & - & $4.3 \pm 0.4$ & $0.002 \ddagger$ \\
\hline ocdipital cliws length (cm) & $2.0 \pm 0.4$ & - & - & $2.6 \pm 0.5$ & $0.001 \neq$ \\
\hline angle of Twining's Iine to tentorium & $39.0 \pm 6.7$ & - & - & $40.4 \pm 3.8$ & 0.45 \\
\hline
\end{tabular}

The obstruction to the transmission of pressure across the foramen magnum was no longer present (slopes of rate of rise in lumbar thecal pressure: preoperatively $4.2 \pm 1.8 \mathrm{~mm} \mathrm{Hg} / \mathrm{second}$ compared with postoperatively $6.9 \pm 2.4 \mathrm{~mm} \mathrm{Hg} / \mathrm{second} ; \mathrm{p}=0.006$ ) (Figs. 3 and 4). Cine MR imaging revealed that the mean velocity of CSF at the foramen magnum was similar to that measured before surgery but that the peak flow rate of CSF was increased in the caudal direction (before surgery $1.5 \pm 0.9 \mathrm{ml} / \mathrm{second}$; after surgery $2.4 \pm 0.9 \mathrm{ml} / \mathrm{second} ; \mathrm{p}=0.03$ ) but not in the rostral direction (before surgery $-1.5 \pm 1.0$ $\mathrm{ml} / \mathrm{second}$; after surgery $-2.2 \pm 2.2 \mathrm{ml} / \mathrm{second} ; \mathrm{p}=0.82$ ) and that the area of the CSF pathways at the foramen magnum increased (before surgery $1.1 \pm 0.6 \mathrm{~cm}^{2}$; after surgery $3.2 \pm 2.8 \mathrm{~cm}^{2} ; \mathrm{p}=0.04$ ). The maximum velocity of syrinx fluid in the inferior direction during systole decreased (before surgery 17.9 $\pm 11.9 \mathrm{~mm} \mathrm{Hg}, 1$ week after surgery $9.2 \pm 9.8 \mathrm{~mm} \mathrm{Hg}, 6$ months after surgery $11.9 \pm 9.4 \mathrm{~mm} \mathrm{Hg} ; \mathrm{p}=$ $0.05, p=0.03$, respectively) (Fig. 5 lower). The mean cervical subarachnoid pressure decreased after surgery (before surgery $15.5 \pm 5.6 \mathrm{~mm} \mathrm{Hg}$, after surgery $11.2 \pm 2.5 \mathrm{~mm} \mathrm{Hg} ; \mathrm{p}=0.006$ ) as did the mean lumbar subarachnoid pressure (before surgery $13 \pm 3$, after surgery $11.2 \pm 2.3 ; \mathrm{p}=0.05$ ) (Table 1 ). Craniospinal compliance increased from $3.3 \pm 2.3 \mathrm{ml} \mathrm{CSF} / \mathrm{mm} \mathrm{Hg}$ to $5.6 \pm 4 \mathrm{ml} \mathrm{CSF} / \mathrm{mm} \mathrm{Hg}(\mathrm{p}=0.05)$. The longitudinal extent and diameter of the syrinx on MR imaging was much smaller $(\mathrm{p}<0.0001)$ (Fig. 2 right, Table 3).

\section{Clinical Symptoms and Signs}

Before surgery, the patients manifested the typical symptoms (headache, dysesthetic pain, weakness, clumsy gait, and loss of sensation) and signs (muscle weakness, atrophy, spasticity, sensory deficit, and ataxia) associated with syringomyelia and the Chiari I malformation.[3] Symptoms had improved more than signs as of the 6-month postoperative examination (Table 4). Neurological examinations were 
repeated annually and the results remained static in all patients. The surgical procedure consistently corrected the pathophysiological consequences of the Chiari I malformation, induced remission of the syrinx, and stabilized the patient's clinical picture, but it was associated with limited improvement, presumably a result of irreversible injury to the spinal cord by the syrinx.

\begin{tabular}{|c|c|c|c|c|c|c|c|c|}
\hline \multicolumn{9}{|c|}{$\begin{array}{c}\text { TABLE } 4 \\
\text { CLINICAL RESULTS IN } 20 \text { PATIENTS WITH BOTH CHIARII I MALFORMATION } \\
\text { AND SVNRINGOMVELA }\end{array}$} \\
\hline \multirow[b]{2}{*}{ Symptomisign } & \multicolumn{4}{|c|}{$\begin{array}{l}\text { Preop Status } \\
\text { (no. of patients) }\end{array}$} & \multicolumn{4}{|c|}{$\begin{array}{l}\text { Postop Stat us } \\
\text { (no. of patients) }\end{array}$} \\
\hline & $\begin{array}{l}\text { A.t- } \\
\text { Sent }\end{array}$ & Mild & $\begin{array}{l}\text { Mod- } \\
\text { erate }\end{array}$ & $\begin{array}{l}\text { Se- } \\
\text { vere }\end{array}$ & $\begin{array}{l}\text { A.t- } \\
\text { sert }\end{array}$ & Mild & $\begin{array}{l}\text { Mod } \\
\text { erate }\end{array}$ & $\begin{array}{l}\text { Se } \\
\text { vere }\end{array}$ \\
\hline symptom & & & & & & & & \\
\hline headache & 12 & 3 & 5 & 0 & 18 & 2 & 0 & 0 \\
\hline dysesthetic pain & 7 & 3 & 9 & 1 & 11 & 7 & 2 & 0 \\
\hline subjective meakness & 10 & 8 & 0 & 2 & 14 & 4 & 0 & 2 \\
\hline $\begin{array}{l}\text { sensory loss by } \\
\text { history }\end{array}$ & 2 & 5 & 11 & 2 & 10 & 8 & 0 & 2 \\
\hline $\begin{array}{l}\text { im paired am bulation } \\
\text { sian }\end{array}$ & 8 & 9 & 2 & 1 & 14 & 4 & 1 & 1 \\
\hline $\begin{array}{l}\text { meakness by } \\
\text { examination }\end{array}$ & 14 & 4 & 2 & 0 & 16 & 4 & 0 & 0 \\
\hline atrophy & 16 & 2 & 2 & 0 & 16 & 2 & 2 & 0 \\
\hline spasticity & 15 & 1 & 2 & 2 & 16 & 2 & 0 & 2 \\
\hline ataxia & 15 & 3 & 2 & 0 & 15 & 4 & 1 & 0 \\
\hline $\begin{array}{l}\text { sensoryloss by } \\
\text { examination }\end{array}$ & 4 & 3 & 11 & 2 & 8 & 7 & 3 & 2 \\
\hline
\end{tabular}

The research testing was well tolerated and there were no new neurological deficits associated with it. Two patients had headaches lasting 4 to 6 days after lumbar puncture.

\section{DISCUSSION}

The results of this study establish that there are significant abnormalities in the CSF physiology of patients with syringomyelia, which support a new theory of progression of syringomyelia: the Chiari I malformation produces an anatomical and physiological block to the flow of CSF, as was shown by the results of conventional MR imaging, phase-contrast cine MR imaging, and Queckenstedt's test. Because expulsion of CSF into the cervical subarachnoid space is the normal compensatory mechanism in response to brain expansion during cardiac systole (Fig. 8 upper), brain expansion forces the cerebellar tonsils (as shown on intraoperative ultrasound images) into the partially enclosed spinal subarachnoid space (Fig. 8 center). Because the partially enclosed spinal subarachnoid space has low compliance to abrupt changes in volume, tonsillar descent results in enlarged cervical subarachnoid pulse pressure waves, as demonstrated by the results of the CSF pressure recordings. The syrinx pressure recordings documented transmission of the subarachnoid pressure wave through the wall of the spinal cord. Pulsatile caudal flow of the syrinx fluid, which leads to syrinx progression, is seen on cine MR imaging studies. 

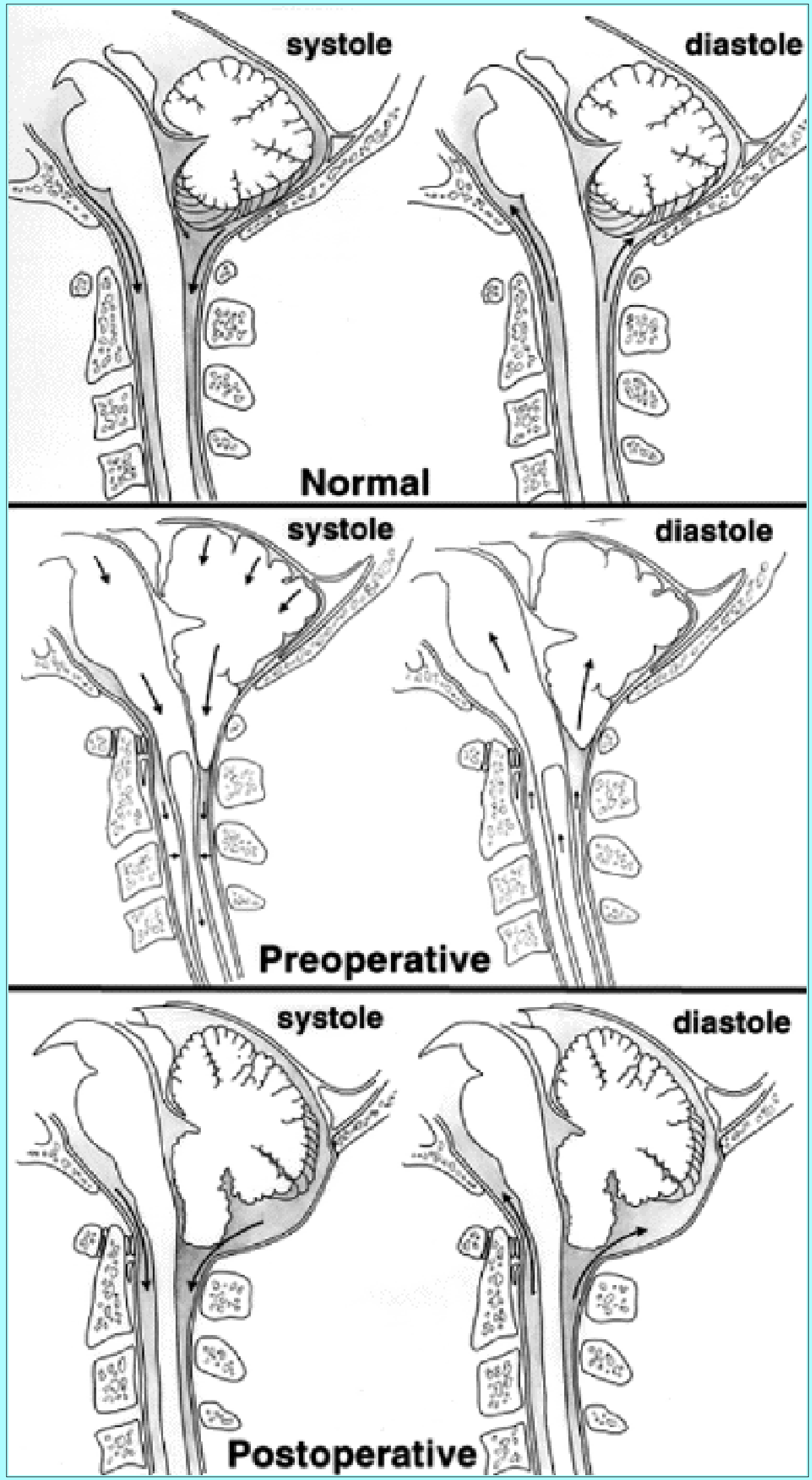

Fig. 8. Illustrations showing normal anatomy and flow of CSF in the subarachnoid space at 
the foramen magnum during the cardiac cycle in a normal healthy volunteer (upper); obstructed flow of CSF in the subarachnoid space at the foramen magnum resulting in the cerebellar tonsils' acting as a piston on the cervical subarachnoid space, creating cervical subarachnoid pressure waves that compress the spinal cord from without and propagating syrinx fluid movement (center); and relief of the obstruction of the subarachnoid space at the foramen magnum, eliminating the mechanism of progression of syringomyelia (lower).

Following surgery that expands the CSF pathways at the craniocervical junction, conventional MR imaging, phase-contrast cine MR imaging, and Queckenstedt's test demonstrated relief of the anatomical and physiological block at the foramen magnum (Figs. 2 right and 8 lower). Relief of the block reduces pulsation of the cerebellar tonsils, increases compliance, and reduces cervical pulse pressure. The velocity of the pulsatile flow of the syrinx fluid falls, the syrinx size decreases, and the patient's neurological signs and symptoms stabilize or improve. The surgical procedure corrects the pathophysiological consequences of the Chiari I malformation while avoiding surgical distortion of the cerebellum. It also preserves the arachnoid membrane, preventing blood products, which can lead to subarachnoid scarring, from entering the subarachnoid space. In our patients, the degree of subarachnoid scarring at the foramen magnum was not extensive, based on ultrasound images and visual inspection through the translucent arachnoid. Clearly, in the uncommon case of a patient with a Chiari I malformation and extensive subarachnoid scarring, simple bone and dural decompression will not eliminate the obstruction to the free flow of CSF within the subarachnoid space and may not induce resolution of syringomyelia.

As well as evaluating the proposed mechanism of syrinx progression, in this study we also evaluated alternative theories of syrinx progression. The results are inconsistent with the hydrodynamic theory, which presumes that transmission of pressure waves from the fourth ventricle to the syrinx produces syrinx progression.[7] Only one patient had radiographic evidence of a connection between the syrinx and fourth ventricle. In all patients, including the one with that connection, intraoperative ultrasonography demonstrated that the syrinx contracted during cardiac systole (Fig. 7), which is the opposite of what would be expected to occur if systolic pressure waves were entering the syrinx from the fourth ventricle. In addition, these findings suggest that it is unnecessary to place a piece of muscle into the obex of the fourth ventricle, a surgical technique that seeks to prevent CSF from entering the central canal of the spinal cord and risks injury to and dysfunction of the hypoglossal and vagal nuclei of the medulla oblongata, $[7,13]$ to place shunt tubing through the spinal cord and into the syrinx to "drain the syrinx,"[13] or to coagulate or resect the cerebellar tonsils.[3]

The results similarly refute the theory that a difference between intracranial and spinal subarachnoid pressures during the Valsalva maneuver results in syrinx progression.[19,20] As we mentioned earlier, radiographic confirmation of a CSF pathway between the fourth ventricle and syrinx only occurred in one patient. In addition, the syrinx diameter did not change during the Valsalva maneuver, as predicted by this theory. The magnitude of the craniospinal pressure differential was much lower in this study compared with that reported by Williams,[20] possibly because of differences in the techniques used for recording pressure differentials; our recordings occurred in horizontal patients in whom anesthesia had been induced, whereas Williams' recordings were made in awake patients in the sitting position. The horizontal position has the advantage of maintaining equal hydrostatic pressure on the ventricular and intrathecal needles, whereas in the sitting position, the dependent intrathecal needle is under more hydrostatic pressure than the ventricular needle, even though ventricular and intrathecal pressures are recorded as equal at a common reference point. When the patient is in the sitting position, increased 
hydrostatic pressure favors leakage of CSF around the dependent intrathecal needle during and immediately following the performance of a Valsalva maneuver, which may produce factitious recordings of craniospinal pressure differentials. Other authors who have examined patients with Chiari I and syringomyelia also have not detected a craniospinal pressure differential during the Valsalva maneuver.[2]

The radiological studies revealed expansion of the CSF pathways after decompression of the foramen magnum and posterior fossa. Opening the CSF pathways did not require entrance into the subarachnoid space or dissection or resection of cerebellar tissue, as is performed by some surgeons.[3,13] A comparison of pre- and postoperative $\mathrm{T}_{1}$-weighted $\mathrm{MR}$ images also demonstrated that expansion of the posterior fossa results in a normal cerebellar structure, with ascent of the cerebellar tonsils into the posterior fossa and the acquisition of a rounded, rather than a pointed, shape (Table 3 and Fig. 2).[1] Because the Chiari I malformation results from a posterior fossa that is smaller than normal in the majority of cases[11,15,18] and of insufficient size to contain the cerebellum and brainstem,[10] rather than a primary abnormality of the cerebellum, the surgical procedure directly addresses the underlying pathological entity. This return of tonsillar shape to normal suggests that the abnormal shape of the cerebellar tonsils seen in Chiari I malformation is acquired by tonsillar impaction in the foramen magnum and the upper portion of the spinal canal rather than resulting from a congenital abnormality of the tonsils, as has been generally thought.

The pathophysiology demonstrated in the current study also explains the basis by which alternative treatments, such as shunting of syrinx fluid or CSF, arrest syrinx progression. Shunts from the syrinx to the subarachnoid space provide a route of efflux for syrinx fluid during the external cord compression that occurs during cardiac systole. When CSF or syrinx fluid is shunted to the peritoneal cavity, cervical subarachnoid and syrinx mean and pulse pressures are reduced and CSF compliance is increased. Despite these beneficial physiological effects, shunts have several disadvantages: for insertion they require a myelotomy, which is occasionally associated with acute or delayed injury to the spinal cord; they are prone to occlusion, with a functional halflife of approximately 4 years; [14] they are foreign bodies that can become infected and require removal; and shunting the spinal subarachnoid space may increase cerebellar tonsillar herniation and exacerbate or induce cerebellar or medullary symptoms.[21] Although shunts arrest the mechanism of progression of syringomyelia, their shortcomings make their routine use undesirable.

No clinical or radiographic recurrence of syringomyelia occurred during the follow-up period $(3.3 \pm 1.8$ years). This contrasts with the natural history of syringomyelia, which is one of progressive neurological deterioration lasting months to years. Untreated patients examined during the era of computerized tomography myelography and MR imaging experience progression with an incidence of 11 to $24 \%$ per year. $[4,9,17]$ Despite the relatively short follow-up period in this study, the improvement in neurological signs and symptoms has been sustained at a higher level than could be expected from the natural history of the condition, with stable or improved neurological function in all patients. The surgical procedure consistently corrected the pathophysiological consequences of the Chiari I malformation, induced remission of the syrinx, and stabilized the patient's clinical picture, but was associated with limited improvement, presumably a result of irreversible injury to the spinal cord by the syrinx. Early diagnosis and treatment of syringomyelia are essential if development of irreversible neurological deficits is to be prevented.

\section{CONCLUSIONS}


Our proposal of syrinx pathogenesis is confirmed by the physiological and anatomical studies performed before, during, and after craniocervical decompression for Chiari I and syringomyelia in this study. The findings indicate that the mechanism of syrinx origin and resolution arises outside, not inside, the spinal cord. Thus, extraarachnoidal craniocervical decompression and duraplasty reverses the mechanism of syringomyelia progression without invading the central nervous system parenchyma or the CSF pathways and consistently provide a safe and effective treatment of patients with Chiari I and syringomyelia.

\section{Acknowledgments}

We are indebted to Drs. W. Brooks, J. Bean, and R. Travis, Lexington, Kentucky; Dr. S. McIntyre, Salt Lake City, Utah; and Dr. C. Haworth, Lumberton, North Carolina, for their support in the conduct of this study.

\section{References}

1. Barkovich AJ, Wippold FJ, Sherman JL, et al: Significance of cerebellar tonsillar position on MR. AJNR 7:795-799, 1986

2. Barnett HJM, Foster JB, Hudgson P: Syringomyelia. Philadelphia: WB Saunders, 1973, pp 79-103

3. Batzdorf U: Syringomyelia related to abnormalities at the level of the craniovertebral junction, in Batzdorf U (ed): Syringomyelia: Current Concepts in Diagnosis and Treatment. Baltimore: Williams \& Wilkins, 1991, pp 163-182

4. Boiardi A, Munari L, Silvani A, et al: Natural history and postsurgical outcome of syringomyelia. Ital J Neurol Sci 12:575-579, 1991

5. Boman K, Iivanainen M: Prognosis of syringomyelia. Acta Neurol Scand 43:61-68, 1967

6. Brewis M, Poskanzer DC, Rolland C, et al: Neurological disease in an English city. Acta Neurologica Scand Suppl 24:1-89, 1966

7. Gardner WJ, Angel J: The mechanism of syringomyelia and its surgical correction. Clin Neurosurg 6:131-140, 1959

\section{Lakke JPWF: Queckenstedt's Test. Electromanometric Examination of CSF Pressure on 1969} Jugular Compression and its Clinical Value. Amsterdam: Excerpta Medica, 1969

9. Mariani C, Cislaghi MG, Barbieri S, et al: The natural history and results of surgery in 50 cases of syringomyelia. J Neurol 238:433-438, 1991

10. Nishikawa M, Sakamoto H, Hakuba A, et al: Pathogenesis of Chiari malformation: a morphometric study of the posterior cranial fossa. J Neurosurg 86:40-47, 1997

11. Nyland H, Krogness KG: Size of the posterior fossa in Chiari type 1 malformation in adults. Acta Neurochir 40:233-242, 1978

12. Oldfield EH, Muraszko K, Shawker TH, et al: Pathophysiology of syringomyelia associated with Chiari I malformation of the cerebellar tonsils. Implications for diagnosis and treatment. J Neurosurg 
80:3-15, 1994

13. Rhoton AL Jr: Microsurgery of syringomyelia and syringomyelic cord syndrome, in Schmidek HH, Sweet WH (eds): Operative Neurosurgical Techniques, ed 2. Philadelphia, WB Saunders, 1988, pp $1307-1326$

14. Sgouros S, Williams B: A critical appraisal of drainage in syringomyelia. J Neurosurg 82:1-10, 1995

15. Stovner LJ, Bergan U, Nilsen G, et al: Posterior cranial fossa dimensions in the Chiari I malformation: relation to pathogenesis and clinical presentation. Neuroradiology 35:113-118, 1993

16. Tachibana S, Iida H, Yada K: Significance of positive Queckenstedt test in patients with syringomyelia associated with Arnold-Chiari malformations. J Neurosurg 76:67-71, 1992

17. Van Calenbergh F, Hoorens G, Van Den Bergh R: Syringomyelia: a retrospective study Part II. Diagnostic and therapeutic approach. Acta Neurol Belg 90:100-110, 1990

18. Vega A, Quintana F, Berciano J: Basichondrocranium anomalies in adult Chiari type I malformation: a morphometric study. J Neurol Sci 99:137-145, 1990

19. Williams B: The distending force in the production of "communicating syringomyelia." Lancet 2:189-193, 1969

20. Williams B: Simultaneous cerebral and spinal fluid pressure recordings. 2. Cerebrospinal dissociation with lesions at the foramen magnum. Acta Neurochir 59:123-142, 1981

21. Williams B: Syringomyelia. Neurosurg Clin North Am 1:653-685, 1990

Manuscript received January 29, 1999.

Accepted in final form April 9, 1999.

Address reprint requests to: John D. Heiss, M.D., Surgical Neurology Branch, National Institutes of Health, 10 Center Drive, 10-5D37, MSC-1414, Bethesda, Maryland 20892-1414. email: heissjd@codon.nih.gov. 